Review

\title{
A Systems Dynamics Approach to Explore Traffic Congestion and Air Pollution Link in the City of Accra, Ghana
}

\author{
Frederick A. Armah ${ }^{1, *}$, David O. Yawson ${ }^{2}$ and Alex A.N.M. Pappoe ${ }^{1}$ \\ 1 Department of Environmental Science, School of Biological Sciences, University of Cape Coast, \\ Cape Coast, Ghana; E-Mail: anmpappoe@yahoo.com \\ 2 School of Agriculture, University of Cape Coast, Cape Coast, Ghana; E-Mail: oskidoo@yahoo.com \\ * Author to whom correspondence should be addressed; E-Mail: atoarmah@yahoo.com; \\ Tel.: +233-24-9483014; Fax: +233-42-32709.
}

Received: 4 December 2009 / Accepted: 7 January 2010 / Published: 13 January 2010

\begin{abstract}
Economic development and urbanization poses myriad challenges to transportation systems in relation to negative externalities such as traffic congestion and environmental health risks. Accra, the capital of Ghana, faces mounting urban planning problems, for example traffic congestion, air pollution, traffic safety, and land use planning, among others. The paper aims to provide a system dynamics perspective of the problems. Most of the drivers and cause-effect relationships of traffic congestion and its attendant air pollution are investigated and analyzed using causal loop diagrams. The paper further suggests mechanisms by which the negative externalities associated with road transport in the city of Accra can be addressed.
\end{abstract}

Keywords: traffic congestion; atmospheric pollution; policy; system dynamics; urban planning; Ghana

\section{Introduction}

The connection between traffic congestion and air pollution has received much attention in sustainable development discourse. Particularly in developing countries, where car ownership is still comparatively low, the issue is a source of intense debate. In this paper, we explore the link between traffic congestion and air pollution in the city of Accra, Ghana. The paper is organised into six parts. 
First, we introduce the paper with an outline of traffic congestion in Accra and its underlying drivers. Then as part of the introduction, we give a brief overview of the levels of atmospheric pollutants in the ambient environment of Accra; and motivate the use of systems dynamics to explore the link between traffic congestion and air pollution. The study is then contextualized and Accra is compared with other cities in the developing world. The next two sections are devoted to analysis of the situation in Accra using causal loop diagrams. The fourth and fifth sections capture suggestions on how the problem can be managed. Finally we conclude the paper by highlighting the policy instruments that must be put in place to address the issue of traffic congestion and its attendant air pollution.

Accra $\left(5^{\circ} 33^{\prime} \mathrm{N}\right.$ and $\left.0^{\circ} 13^{\prime} \mathrm{W}\right)$ is the capital city and main administrative and commercial centre of Ghana. Accra's population is growing at a nearly $4 \%$ growth rate with attendant traffic congestion and air pollution [1]. Accra had a population of $1,659,000$ in 2000, while the populations of the two urban centres adjacent to it were: Tema 506,000 and Ga 550,000 [2]. It is estimated that the combined effect of growth and migration will increase the population of the three areas to just under 4 million by 2013, and by 2023 the combined population of the three assemblies (Accra, Tema and Ga) will exceed 5 million. Population growth and increasing rates of car ownership are expected to increase the number of cars in the area from 181,000 in 2004 to over 1 million in 2023 [2]. Under the prevailing conditions less than 5\% of the population of Ghana own private motor vehicles [2]. Over 50,000 vehicles per day at certain points have been recorded for Accra during weekends [2]. On a typical weekday 270,000 vehicle trips are made into, or out of, the Accra central area [2]. Approximately 1.3 million passenger trips per day are estimated to enter or leave the area within the Accra Ring Road and 1.6 million passenger trips into or out of the area within the motorway extension [2]. Almost $84 \%$ of these passenger trips are made by public transport [2]. Over half (56\%) of daily passengers are carried by mini vans, and a further $15 \%$ by taxi [2]. Approximately 1 million passenger trips are made each day into and out of the central area of Accra using mini vans and taxis [2]. These vehicles are inefficient in terms of the amount of road space used, and congestion caused, to transport each passenger. Congestion is a major problem on arterial routes with $70 \%$ of major roads operating at unacceptable level of service at some time during the day $(<20 \mathrm{~km} / \mathrm{h})[2]$. Considerable scope therefore exists to improve the efficiency of people movement through a shift from low capacity public transport vehicles to large and double-decker or articulated buses with the potential to carry over 100 passengers. Government control over the operation of public transport is very limited; however, the private operations are strictly controlled by trade unions. The overall quality of public transport is poor, most vehicles are old, and maintenance standards are extremely low. High vehicle maintenance costs arising from poor road surfaces and limitations imposed on earnings by the acute congestion on the urban roads constrain the operators to invest in new public transit vehicles, a situation which has implications for the levels and extent of emissions of air pollutants and the effect on human health [1-3].

Thousands of studies have been undertaken to examine the link between environmental pollution and health. The extent to which environmental pollutants affect human health depends on socio-economic factors, levels of epidemiological surveillance and the extent of environmental contamination [4-6]. While there are many uncertainties as to some of the precise mechanisms involved in connecting human health impacts and pollutants, a number of studies have demonstrated strong links. Among the best-described impacts is the impact of airborne lead on human health. Lead 
was originally added to petroleum products (now banned in most parts of the world as a petrol additive) to reduce engine knocking and increase combustion efficiency. In Ghana it is no longer used for this purpose. The Environmental Protection Agency of Ghana (EPA-Ghana) in collaboration with the United Nations Environment Programme (UNEP) and the United States Environmental Protection Agency (USEPA) set up the first comprehensive air quality monitoring programme between March 2005 and December 2008. The pollutants measured for roadside locations include Carbon monoxide $(\mathrm{CO})$, particulate matter $10\left(\mathrm{PM}_{10}\right)$, sulphur dioxide $\left(\mathrm{SO}_{2}\right)$, Nitrogen dioxide $\left(\mathrm{NO}_{2}\right)$, lead $(\mathrm{Pb})$ and Manganese (Mn). A total of 745 roadside samples were collected. Seventy-five percent exceeded the EPA-Ghana 24-hour PM-10 air quality guideline of $70 \mu \mathrm{g} / \mathrm{m}^{3}$, and $87 \%$ exceeded the WHO Air quality guideline for 24-hour $\mathrm{PM}_{10}$ of $50 \mu \mathrm{g} / \mathrm{m}^{3}$ [7]. There is significant reduction in the roadside lead levels from a range of $2-188 \mu \mathrm{g} / \mathrm{m}^{3}$ in (2002-2003) before the phase out of leaded gasoline to a range of $0-1.97 \mu \mathrm{g} / \mathrm{m}^{3}$ in $2005-2008$ (below the Annual EPA-Ghana guideline of $2.5 \mu \mathrm{g} / \mathrm{m}^{3}$ ). Particulate manganese concentration ranged from $0.0001-0.64 \mu \mathrm{g} / \mathrm{m}^{3}$, all the results were below the 24-hour EPA-Ghana guideline of $1.0 \mu \mathrm{g} / \mathrm{m}^{3} . \mathrm{SO}_{2}$ concentration measured at the roadside locations were below the 24-hour EPA guideline of $38.4 \mathrm{ppb}$ for residential and $57.5 \mathrm{ppb}$ for industrial areas while $30 \%$ of the $\mathrm{SO}_{2}$ concentrations measured at the roadside sites exceeded the $24 \mathrm{hr}$ WHO guideline of $8 \mathrm{ppb}$ [7]. $\mathrm{NO}_{2}$ concentrations measured at roadside sites were below the 24-hour EPA-Ghana guideline of $79.5 \mathrm{ppb}$. However, $5 \%$ of samples collected at the roadside locations exceeded the 24-hour EPA-Ghana guideline of $32 \mathrm{ppb}$ for residential areas, while, $40 \%$ of $\mathrm{NO}_{2}$ samples collected at the roadside sites exceeded the annual WHO guideline of $20 \mathrm{ppb}$ [7]. Four percent of samples collected at the ten sampling sites exceeded the 8-hour WHO guideline of $50 \mathrm{ppb}$. The CO concentration ranged from 0.174-4.196 ppm. Results for the roadside locations were below the 8-hour EPA-Ghana and WHO guideline of $10 \mathrm{ppm}$. Though ongoing, the interim conclusion of the monitoring programme was that roadside locations have high levels of $\mathrm{PM}_{10}$ compared with residential, industrial and commercial areas [7]. $\mathrm{PM}_{10}$ levels measured during the dry season are far higher than that measured during the wet season. $\mathrm{NO}_{2}$ and $\mathrm{SO}_{2}$ concentrations recorded at the roadside sites were higher than that at the permanent sites. At present, lead and manganese do not seem to be a major issue in Accra's ambient air quality [7].

City planners have typically attempted to reduce traffic congestion and its attendant air pollution by expanding road infrastructure and improving existing ones. But over the years, this approach has met with policy resistance. One factor which features prominently in the discussion is the fact that city planners formulate policies based on event-oriented open (unidirectional) mental models which eventually leads to policy resistance. There is the need to develop in a stepwise process an improved understanding of how the change in traffic volume and the improvement of highway capacity are linked in a number of interacting self-reinforcing feedback loops to understand the problem of policy resistance and the effect that more roads lead to an increase in congestions. This improved understanding can be achieved through systems dynamics. Traffic congestion-air pollution problems are not only very complex, but they also manifest themselves at different spatial scales [8]. Capturing the space and time dimensions of complex problems of this nature, calls for tools such as system dynamics which have the unique capacity to analyze cause-effect and feedback relations across spatio-temporal scales $[9,10]$. The choice of systems dynamics emanates from our quest to understand 
the overall dynamics of the pollution problem by considering the road infrastructure, traffic congestion, air pollution and various stakeholders as one system of interacting parts over time and space.

\subsection{Aims and Objectives}

The paper aims to:

- Provide a system dynamics perspective of the problem of traffic congestion and air pollution in Accra.

- Examine the cause-effect relations, delays and feedback loops in the system that serve to generate policy resistance

- Propose policy strategies to address the issue within a long time horizon

\subsection{The Context}

A number of institutional reforms across spatial-temporal scales have occasioned the present transport situation in Ghana. The reform process of the transport sector in Ghana dates back to the early 1970s. In the wake of a study commissioned to propose ways to improve the construction and maintenance of roads, Decree 298 (1974) established the Ghana Highway Authority (GHA) under the Ministry of Works and Housing. The GHA was given responsibility for the administration, development, and maintenance of all public highways and related facilities in Ghana [11]. Urban roads were managed by city and municipal councils under the Ministry of Local Government. These changes reduced the number of institutions responsible for roads to only five agencies under two ministries. The adoption of structural adjustment policies including liberalisation of the economy, following the virtual collapse of the economy in the early 1980s, led to significant improvement in transport and the importation of fleets of vehicles both new and slightly used ones [12]. By 1981, further institutional consolidation took place. All feeder roads were placed under the Department of Feeder Roads (DFR) within the Ministry of Works and Housing. In 1982, a new Ministry of Roads and Highways (MRH) was formed from the previous Public Works Department. GHA and DFR were moved, and placed under the authority of the new ministry. In 1988, the responsibility for urban road maintenance was shifted from the local authorities (under the Ministry of Local Government) into the newly created Department of Urban Roads (DUR) in the Ministry of Roads and Highways. Thus, by the end of the 1980s, the institutional structure that exists today was in place, consisting of a single ministry, the Ministry of Roads and Highways, with three specialized agencies that manage Ghana's almost 30,000 km road network [11]. The process of this institutional development was decidedly evolutionary, determined along the way by various political, social and economic demands of the time. Thus, it could be argued that the current institutional structure is less the result of a planned reform process, than a relatively efficient result of fortunate circumstances. The creation of the Ministry of Roads and Highways elevated road sector issues to the cabinet level, thereby providing leverage for budget financing through the Ministry of Finance. The MRH provides unified planning, policy formulation, implementation, and monitoring the sector. Ghana has one of the oldest road funds in Africa. The Ghana Roads Fund was established in July 1985, and was updated by the 1996 Ghana 
Highway Authority Act [11]. The main objective of the road fund is to finance routine and periodic maintenance of roads, including assistance to the metropolitan, municipal, and district assemblies in maintaining roads. The fund is financed principally by a fuel levy, with small additional revenue derived from vehicle inspection fees and tolls from roads and bridges.

In many ways, however, Accra epitomizes an automobile dependent society. Automobile dependency is a concept that refers to transportation (technology) and land use patterns (geography) resulting in high levels of automobile use and reduced transport options [13,14]. Within the context of this paper, automobile dependency means abundant use of cars due to lack of other transport options or due to insufficient incentives to use alternative modes of transport. Thus, an automobile dependent society like Accra may have a multi-modal transport system in place but at the same time some factors (insufficient incentives) cause a higher use of cars. These factors are numerous and differ in nature: objective factors may be for example prices (expensive public transport together with low costs of petrol and parking), low reliability or simply non-existence of alternative public transport (as in the virtual collapse of the Accra rail system); subjective factors can be for example comfort or manifestation of social status (prestige).

\subsection{How Does Accra Compare to Other Cities in Developing Countries}

The urban transport system in Ghana particularly in Accra, is characterised by the congested central areas of the cities, poor quality of service from public transport operators, high exposure to road accidents, and poor environmental standards [15]. This is seen in long commuting times and journey delays, lengthy waiting times for public transport both at and between terminals, high accident rates, and localised poor air quality [16]. Nevertheless this situation is not restricted to Ghana. In other cities of developing countries across Asia and South-America such as Hanoi, Bogota and Santiago, the circumstances are exacerbated [15-18]. The dire traffic congestion situation is even worse in megacities such as Bangkok, Manila, Sao Paulo, Shanghai and Mexico City $[18,19]$. The extent of traffic congestion in these cities is a continuum with the megacities concentrated to one end of the congestion extreme [19]. In addition to the afore-mentioned characteristics, poor vehicle condition and poor infrastructure for non-motorised modes epitomizes Dar-es-Salaam and Hanoi [17,20]. Rapid urbanisation is one of the reasons for the poor state of public transportation in the aforementioned cities. As population continues to increase and as the city continues to sprawl, more people live and work in the city and make more trips within the urban area, often over longer distances. Consequently, the limited capacity of existing transport infrastructure is stretched to the limit and thus, it has become a constraint to cope with the public demand for travel [17].

\section{System Dynamics and Application to Traffic Congestion}

The application of system dynamics to transportation and traffic congestion in particular, is well documented in the literature [21-23]. System Dynamics is a discipline that emerged in the late 1950s, as an attempt to address dynamically complex long term policy issues in the public and private domain [24]. It is grounded in the theory of nonlinear dynamics and feedback control developed in mathematics, physics and engineering. One reason for the requirement for simulation based analysis of 
the traffic congestion-air pollution problem is the dynamic complexity of the real world. It is said, the real world is a multi-loop, multi-state, non-linear feedback system that reacts to the decision makers' actions in ways both anticipated and unanticipated [25]. That is, the effects of our actions can appear at a distant point in time and space and even with unintended consequences. The elements of dynamic complexity that masks our individual and organizational decision making skills are typically classified as: feedback, non-linearity and time delays.

It is applied to the behavior of human as well as physical and technical systems; thus, system dynamics draws on cognitive and social psychology, economics and other social sciences as well [15]. Since its early application such as Urban Dynamics [26], World Dynamics [27] and Limits to Growth [28], applications on environmental resource management and transport in particular had continually increased [29]. Dynamic problems are characterized by variables that undergo significant change in time. The defining property of a dynamic problem is not merely the variables being dynamic. More critically, in a system dynamics problem, the dynamics of the variables must be closely associated with the operation of the internal structure of some identifiable system [24]. It is said that the dynamics is essentially caused by the internal feedback structure of the system. The "structure" of a system is the totality of the relationships that exist between system variables. The structure of a system operates over time so as to produce the dynamic behavior patterns of the system variables over time. For a real system, the structure is not exactly known. For a "model" of the real system, as in this case, the structure is a representation of those aspects of the real structure that we hypothesize to be important for the problem of interest. For instance, although over speeding on good roads have led to increases in prevalence of accidents; it will not be discussed in this paper because we do not consider it to be part of the traffic congestion-air pollution system. Any system (model) structure consists of causal relations among its variables. A causal relation means that, the input variable has a causal influence on the output variable as shown in Figure 1 where city planners in the business-as-usual manner expand the road infrastructure in order to increase highway capacity.

Figure 1. Determinants of travel time (source: Sterman [24]).

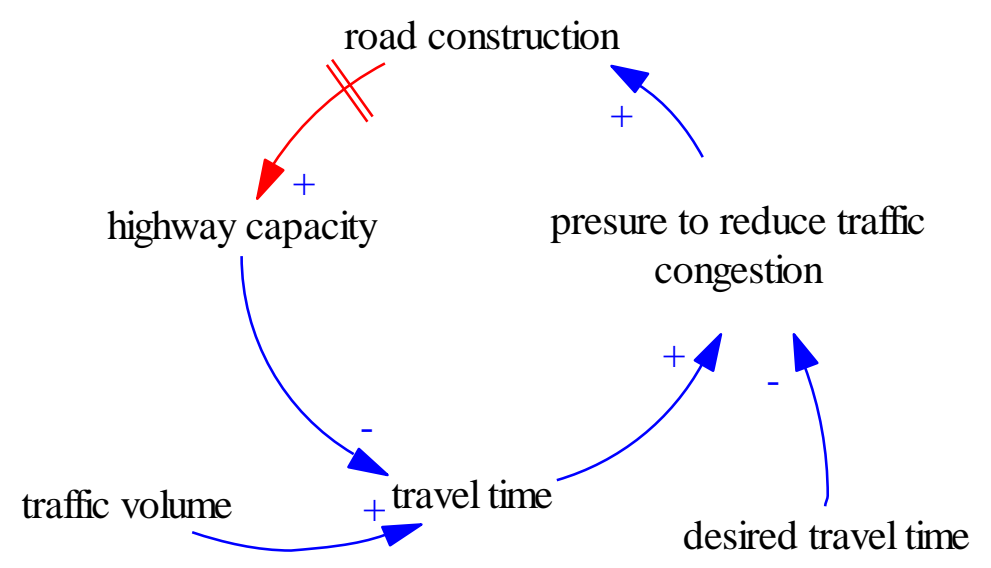

All else being equal, a plus sign (+) over an arrow from $\mathrm{X}$ to $\mathrm{Y}$ implies that if $\mathrm{X}$ increases so does $\mathrm{Y}$, or if $\mathrm{X}$ decreases $\mathrm{Y}$ also decreases. A minus sign (-) indicates an inverse effect. The $(+)$ sign indicates only that changes are reinforced-it does not mean that the effects are necessarily good. The (-) sign indicates only that changes are resisted-it does not mean that the effects are necessarily bad. The 
double line on the arrow linking road construction and highway capacity represents a delay in the system. Delays occur in all systems; it may be of the order of seconds, minutes, hours, months, years, etc. In this case, the delay is of the order of years. In Figure 1 due to the two counter-acting processes the pressure to reduce congestion increases and results in a closed loop to reinforce the need for road construction. There is a compensating feedback as response to the decreased congestion as far as the behaviour is concerned. Driving on the road becomes more attractive. People use less public transport which becomes less attractive since services go down. Hence in the end the whole system is caught in a feed back structure where public transport degrades, traffic increases and in the end congestion increases more and more.

\section{Analysing the Traffic Congestion in Accra}

\subsection{Traffic Congestion and Policy Resistance}

The dynamics of traffic volume is critical to understanding policy resistance and the emergence of unintended outcomes. Figure 2 illustrates the loops that feed into the dynamic complexity of the traffic congestion situation in Accra.

Figure 2. Traffic volume dynamics of traffic congestion in Accra.

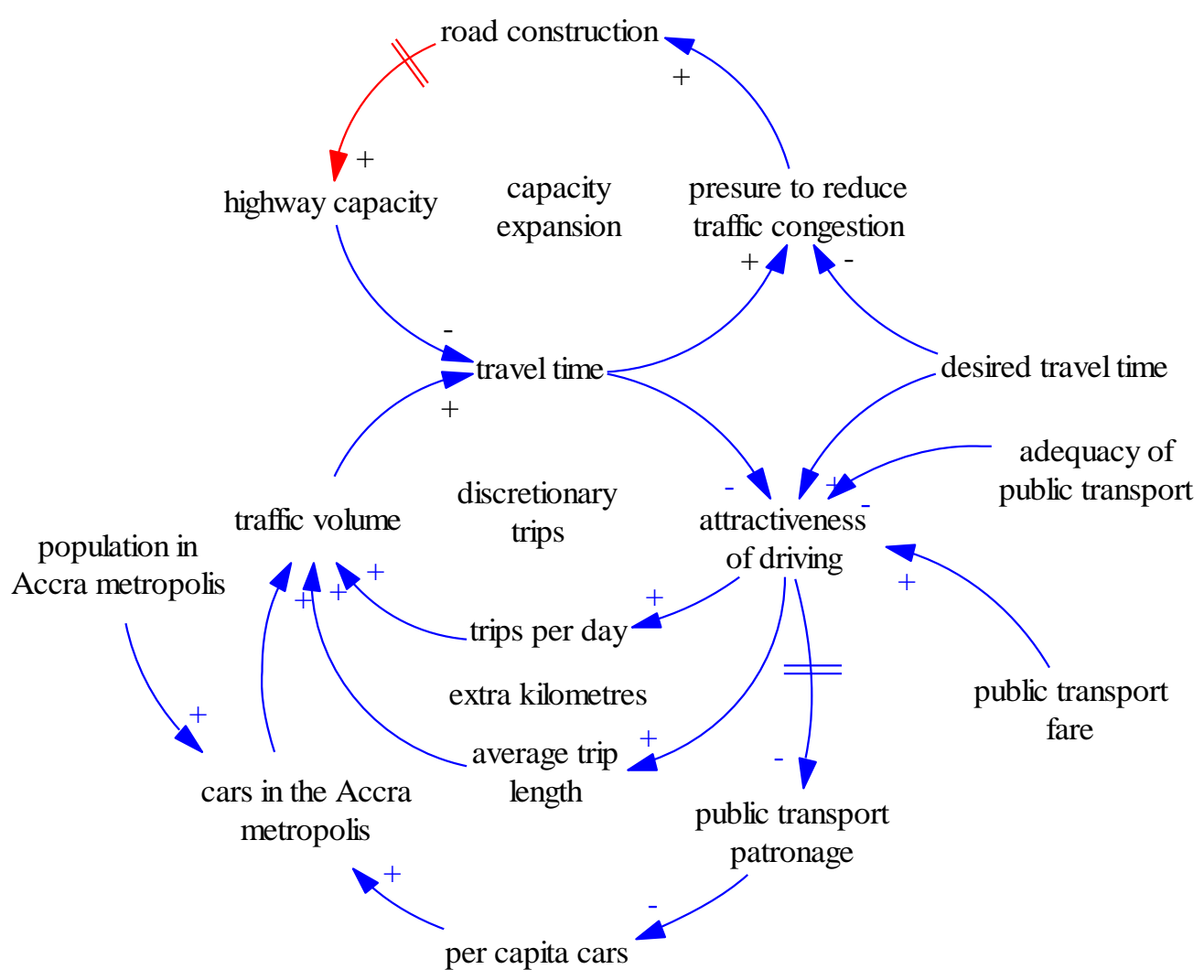

In Figure 2, the desire of the population to reduce travel time increases the pressure to reduce congestion. The desired travel time coupled with inadequate public transport in Accra increases the attractiveness of driving which in turn reduces patronage of public transport services. An increase in 
the attractiveness of driving leads to corresponding increases in trips per day and average trip length. These two factors feed into increased traffic volume. There is a delay in reduction of patronage of public transport arising from the fact that it takes a while for individuals to change their lifestyles and also because most individuals can not afford to buy cars when income levels are low. GDP and livelihoods take considerable time to improve; therefore the shift from public transport to personal cars arising from improved income levels is gradual and often goes unnoticed. This leads to an increase in cars per person. Eventually, the number of cars in the Accra metropolis increases, which in turn leads to an increase in traffic volume. Therefore, even though the original goal was to reduce traffic congestion, the outcome indicates that the feedback loops rather serve to reinforce the problem.

\subsection{Traffic Congestion and Health Risks}

A third dimension of the traffic congestion problem arises when air pollution levels increase due to increases in traffic volume and road expansion as shown in Figure 3.

Figure 3. Road expansion, traffic congestion and air pollution.

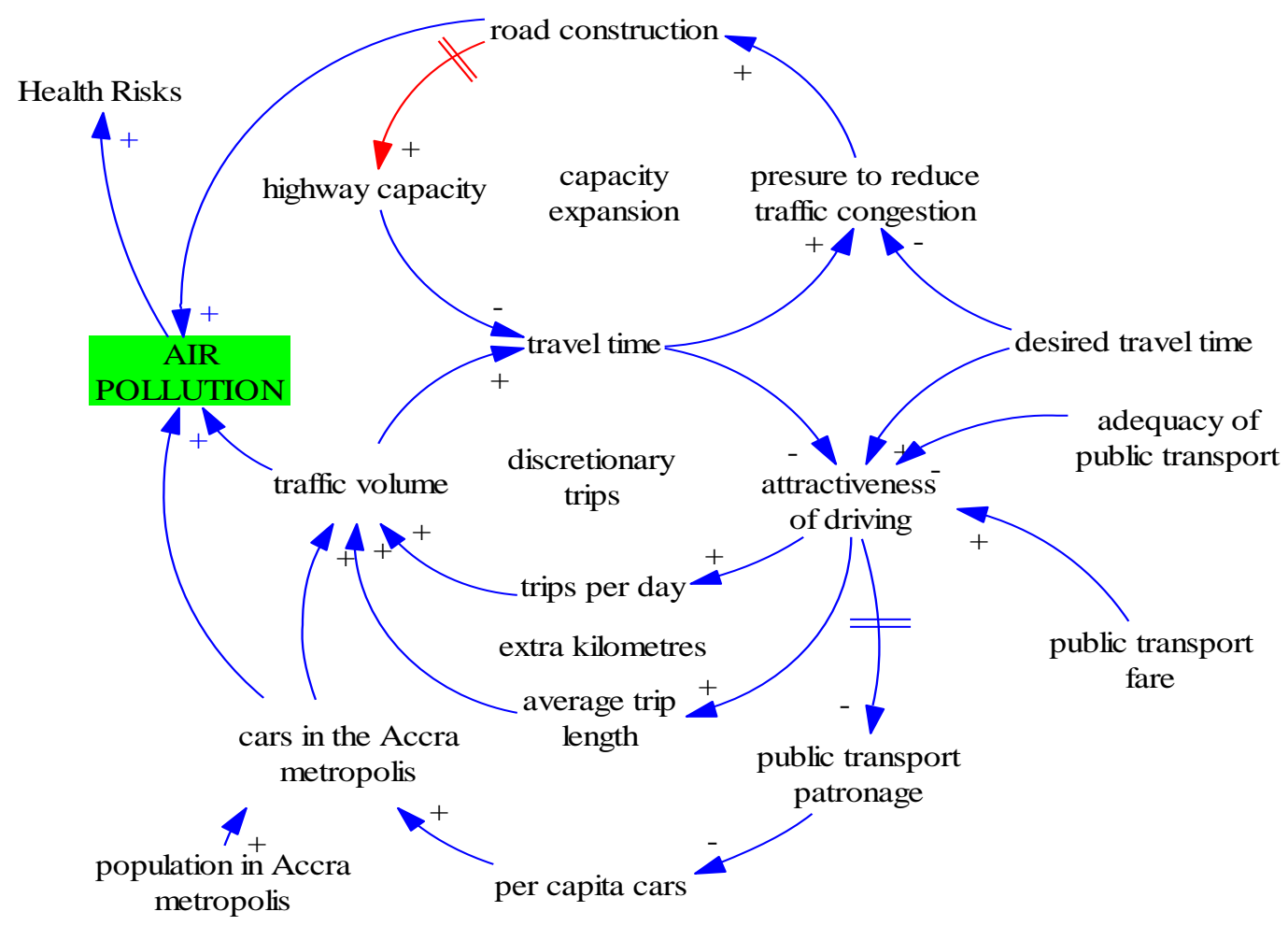

In Figure 3, the environmental impact due to traffic congestion is on the rise. Air quality in Accra is a health risk. The levels of heavy metals $(\mathrm{Pb}, \mathrm{Cr}, \mathrm{Ni}, \mathrm{Cd}$, and $\mathrm{V}), \mathrm{NO}_{\mathrm{x}}$, and $\mathrm{SO}_{2}$ emitted from exhausts of motor vehicles along roads in Accra are relatively high compared to other roads where traffic volume is low [1]. $\mathrm{Pb}$ is persistent therefore it is not surprising that it exists in the roadside environment though it is no longer in use as an octane enhancer. Additionally, expansion in roads leads to the emission of particulate matter which negatively affects the respiratory tract. Within the past 10 years, the Government of Ghana has constructed three major highways (Accra-Kumasi, Accra-Yamoransa, Accra-Aflao) and a significant number of minor roads in response to its 
commitment to the Trans ECOWAS (Economic Community of West African States, regional group consisting of 16 countries founded to foster economic and political integration) Highway policy which seeks to link all the member states by road in order to facilitate trade, investment and regional integration. Within Accra, the Government has in addition constructed three major intersections with a view to meeting the demand for more highway capacity. Significant levels of suspended particulate matter have consequently been released from the construction of these roads. In most cases, no measures were put in place to mitigate the impact of the particulate matter on road users. The health risks and inconvenience that road users endured during the construction of the roads seem to have been in vain because traffic congestion has worsened. In fact, all car users whether private or public interviewed on the Tetteh-Quarshie Interchange, Accra, the largest intersection constructed by the Government in 2007, indicated that their travel time regardless of their destination has increased since the interchange was completed. Some of the interviewees further indicated that their travel time has doubled. We found that individuals using public transit (mini vans and taxi) often had to disembark and continue their journey on foot because it was efficient than remaining in the public vehicles caught in stagnant traffic. This finding was confirmed by [2]. In order to validate the road expansion, traffic congestion and air pollution model, we randomly interviewed 500 individuals in Accra that constitute different stakeholder groups (public transport owners and users, private car owners and users, urban planners, city authorities, the Ministry of Transportation, pedestrians and road contractors, among others). Table 1 summarises the interviews.

Table 1. Summary of the indicators used in the survey of transport sector stakeholders.

\begin{tabular}{|c|c|c|}
\hline Aspect & Indicator name & Perception \\
\hline \multirow[t]{9}{*}{ Economic } & - Average time taken for a home-work journey & 2 hours \\
\hline & - Average distance for a home-work journey & 20 kilometers \\
\hline & $\begin{array}{l}\text { - Average Travel time to formal and informal places of } \\
\text { work in Accra }\end{array}$ & $\begin{array}{l}2 \text { hours. More than } 80 \% \text { indicated } \\
\text { that an increase has occurred }\end{array}$ \\
\hline & $\begin{array}{l}\text { - Level of affordability of transport as a } \% \text { of income by } \\
\text { urban poor }\end{array}$ & About $60 \%$ said that it is low \\
\hline & - Level of fuel prices & All respondents said it is high \\
\hline & $\begin{array}{l}\text { Percentage of Accra dwellers travelling to places of } \\
\text { work by foot }\end{array}$ & $30 \%$ \\
\hline & $\begin{array}{l}\text { - Proportion of individuals which report transport as a } \\
\text { major obstacle to employment }\end{array}$ & $55 \%$ \\
\hline & $\begin{array}{l}\text { Proportion of individuals who report transport as an } \\
\text { obstacle to markets }\end{array}$ & $17 \%$ \\
\hline & $\begin{array}{l}\text { - Proportion of residents that chose place of residence } \\
\text { with transportation as major consideration }\end{array}$ & $74 \%$ \\
\hline \multirow[t]{3}{*}{ Health } & $\begin{array}{l}\text { Average distance to the nearest health facility from } \\
\text { home }\end{array}$ & $5 \mathrm{~km}$ \\
\hline & $\begin{array}{l}\text { - Average travel time to the nearest health facility from } \\
\text { home }\end{array}$ & $\begin{array}{l}30 \text { minutes, but this is increasing } \\
\text { steadily }\end{array}$ \\
\hline & $\begin{array}{l}\text { Environmental impact identified by audits of } \\
\text { transportation programs undertaken. }\end{array}$ & $\begin{array}{l}\text { Respiratory tract infection, } \\
\text { coughing, eye irritation, noise } \\
\text { pollution }\end{array}$ \\
\hline
\end{tabular}


Table 1. Cont.

\begin{tabular}{lll}
\hline Aspect & \multicolumn{1}{c}{ Indicator name } & Perception \\
\hline Health & $\bullet$ & $30 \%$ \\
& $\begin{array}{l}\text { Proportion of households that report transport } \\
\text { constraint on health }\end{array}$ & $35 \%$ \\
& $\begin{array}{l}\text { Proportion that chose health facility based on } \\
\text { proximity }\end{array}$ & 1.5 hours \\
\hline
\end{tabular}

\section{Ways in Which to Address Negative Externalities of Road Transport in Accra}

Often city planners view urban planning as a very different issue from transport planning, transport planning as very different from environmental planning, public transport as very different from emissions control, and so forth. One widely used and long-established approach for emissions analysis is to view emissions in relation to travel volume, fuel efficiency, and vehicle stock [30]. In this framework, emissions are viewed as a vehicle problem, mostly technical in nature. This pulls policymakers in developing countries such as Ghana towards short-term solutions, which often serve the interests of the political establishment. Understanding the urban transport-energy-environment conundrum is more complex than it may seem. The issues to be addressed range from urban planning to emissions control, present to future, local to global environmental issues, technical to human behavior issues, regulation to volunteerism, and a complex interplay of stakeholders from ordinary citizens to the private sector to different levels of government. Measures that fail to capture these issues are likely to encounter policy resistance. It may be necessary to consider the interaction of activity, structure, energy intensity, and fuel factors in dealing with the problem.

Table 2. Factors and challenges in activity, structure, intensity and fuel factors.

\begin{tabular}{|c|c|c|}
\hline Component & Major indicators & Related challenges in Accra \\
\hline $\begin{array}{l}\text { Activity and } \\
\text { Structure }\end{array}$ & $\begin{array}{ll}\text { - } & \text { Income } \\
\text { - } & \text { Rate of urbanization } \\
\text { - } & \text { Rate of motorization } \\
\text { - } & \text { Non-motorized modes } \\
\text { - } & \text { Rate of use of private } \\
& \text { transport modes }\end{array}$ & $\begin{array}{l}\text { - Reducing the need for motorized travel } \\
\text { - Improving efficiency of public transport and } \\
\text { transport systems } \\
\text { - } \quad \text { Limiting private transport such as cars and } \\
\text { their rate of use } \\
\text { - } \quad \text { Reducing congestion by increasing } \\
\text { efficiency of the transport infrastructure }\end{array}$ \\
\hline $\begin{array}{l}\text { Intensity and Fuel } \\
\text { factors }\end{array}$ & 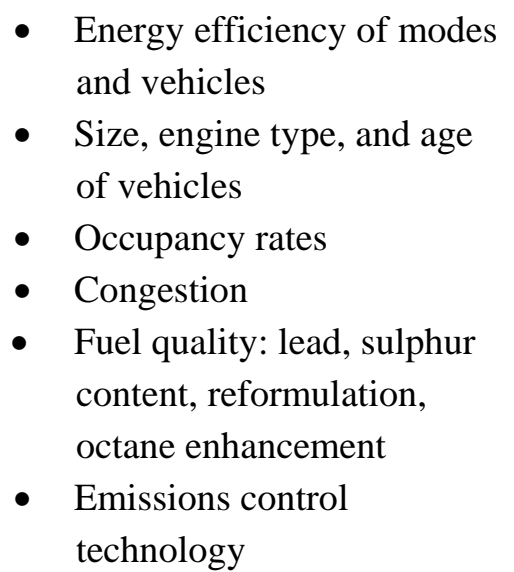 & $\begin{array}{l}\text { - Choosing alternative fuels such as } \\
\text { electricity making it cost effective } \\
\text { - Improving inspection and maintenance } \\
\text { - } \text { systems for in-use vehicles } \\
\text { - } \quad \text { Controlling tailpipe emissions through } \\
\text { efficient technology }\end{array}$ \\
\hline
\end{tabular}


Each of these components is affected by various factors, such as prices, policies, and technologies [31]. Table 2 shows a few of the factors that affect activity, structure, intensity and fuel factors and related challenges in the city of Accra.

For policymakers, behavioral and lifestyle factors govern Activity and Structure, while technology factors govern Intensity and Fuel factors. A reasonable balance between interventions in Activity and Structure on the one hand and Intensity and Fuel factors on the other hand, though necessary, is rarely found. The problem with too great a focus on Intensity and Fuel factors is that Activity and Structure issues are increasing very fast in Accra. The number of car use has doubled in Accra within the last five years. Even if these vehicles are relatively clean, their impact in terms of both increased distances traveled and increased pollution/passenger-km compared with bus (not to mention non-motorized transport modes) means that overall pollution from transport can be rising even if actual vehicles (and their fuels) are improving.

\section{Proposal of Policies to Solve the Traffic Congestion in Accra}

It is evident that the mechanisms that Accra city planners used to solve traffic problems of yesteryears have become the traffic problems of today. There is no panacea to the traffic congestion-air pollution problem in Accra. However, a number of measures can be employed to solve the situation both in the short-and long term. These measures fall within three broad categories: government policy and planning, travel demand management, and supply management.

\section{- Government Policy and Planning}

A cursory look at Figure 3 indicates that population growth arising from urbanization and economic development drives the increase in cars in the Accra metropolis. The root cause namely urbanisation has to be rigorously tackled by making the phenomenon unattractive. Cars are inefficient in terms of the amount of road space used, and congestion caused, to transport each passenger. This means that Government policy and planning has to put economic and policy instruments in place to control further increases in car use while concomitantly stimulating the shift to a public transportation system. For Accra, bus service is the most appropriate means of public transport in the short to medium term. Over the past 8 years, the bus system has improved with the introduction of intercity and metro mass transit bus services but there is still a gap to meet before attaining the desired bus service. The light railway transit system would be an appropriate alternative in the future. Improving traffic condition and environment for pedestrians would be the first priority to increase public ridership.

\section{- Travel Demand Management}

Again, Figure 3 shows that a number of variables feed into travel demand: attractiveness of driving, trips per day, average trip length, and number of cars. A travel demand management system needs to be set up in order to contain the potential increasing number of cars. Many alternatives to control the number of private vehicles are proposed, for example, import tax, car registration fee, vehicle owner fee; different prices of petrol for public and private vehicles, a policy that allows every family to possess only one vehicle. 
Other alternatives to limit road use for private vehicle include the following: toll fee, high parking fee, parking prohibition, among others. It must be mentioned that some of these measures are already in place. However, the effectiveness of the measures in eliciting the needed response is subject to question primarily because of weak institutional and enforcement capacities of the monitoring agencies.

\section{- Supply Management}

Capacity of transportation system in general and road network specifically will invariably expand. Transportation land use in Accra is limited. Government is making frantic efforts to meet international standards. This is underscored by its commitment to the Trans ECOWAS Highway project which seeks to link all the member states by road in order to facilitate trade, investment and regional integration. Transportation planning would therefore be a key answer of the development process. The national transport policy which details the transportation system development of Accra was approved by the government in 2001; however, it is a big capital investment that is beyond the financial capacity of the government of Ghana alone. Therefore, the participation of multi-economic sectors in road network construction has to be vigorously encouraged.

\section{Conclusions}

Economic development and urbanization poses myriad challenges to transportation systems in relation to negative externalities such as traffic congestion and environmental health risks. However, sustainability dictates that the present generation should not compromise the capacity of future generations to meet their needs; a requirement that makes it imperative to deal with the traffic congestion-air pollution nexus head-on. To deal with traffic congestion, many solutions have been proposed in a number of previous studies but with marginal success because the problem was not considered as a system of interacting parts in space and time. In this paper, system dynamics; an effective method was applied to identify related drivers, causes and effects of traffic problem in Accra. Through causal loop diagrams, alternatives were proposed to limit the effectiveness of negative loops. The goal is to stimulate public transport use while decreasing car use in the near future. Based on the analysis, policies mainly economic instruments were proposed to reduce traffic congestion in the city of Accra. Three main measures that policy makers could consider are development of a public transport system, road network expanding and enhancing, and travel demand management alternatives.

\section{References and Notes}

1. Affum, H.A.; Oduro-Afriyie, K.; Nartey, V.K.; Adomako, D.; Nyarko, B.J.B. Bio-monitoring of airborne heavy metals along a major road in Accra, Ghana. Environ. Monit. Assess. 2008, 137, $15-24$.

2. Quarshie, M.L. Integrating cycling in Bus Rapid Transit system in Accra. In Highway and Urban Environment, Proceedings of the 8th Highway and Urban Environment Symposium, Nicosia, 
Cyprus, 12-14 June 2006; Morrison, G.M., Rauch, S., Eds.; Springer Netherlands: Dordrecht, The Netherlands, 2007; pp. 103-116.

3. Carreras, H.A.; Pignata, M.L. Bio-monitoring of heavy metals and air quality in Cordoba City, Argentina, using transplanted lichens. Environ. Pollut. 2002, 117, 77-78.

4. Buckler, D.R.; Grenato, G.E. Assessing Biological Effects from Highway Runoff Constituents; Open File Report 99-240; US Department of Transportation: Northborough, MA, USA, 1999.

5. Cape, J.N.; Tang, Y.S.; van Dijk, N.; Love, L.; Sutton, M.A.; Palmer, S.C.F. Concentrations of ammonia and nitrogen dioxide at roadside verges, and their contribution to nitrogen deposition. Environ. Pollut. 2004, 132, 469-478

6. Sriyaraj, K.; Shutes, R.B.E. An assessment of the impact of motorway runoff on a pond, wetland and stream. Environ. Int. 2001, 26, 433-439.

7. Nerquaye-Tetteh, E. Urban Air Quality Monitoring in Accra: Case Study; Environmental Protection Agency-Ghana: Accra, Ghana, 2009. Available online: http://www.unep.org /urban_environment/PDFs/BAQ09_ghanacasestudy.pdf (accessed on 5 November 2009).

8. Liu, J.G.; Dietz, T.; Carpenter, S.R.; Albertini, M.; Folke, C.; Moran, E.; Pell, A.N.; Deadman, P.; Kratz, T.; Lubchenco, J.; et al. Complexity of coupled human and natural systems. Science 2007, 317, 1513-1516.

9. Haraldsson, H.V.; Olafsdottir, R. Simulating vegetation cover dynamics with regards to long-term climatic variations in sub-arctic landscapes. Glob. Planet. Change 2003, 38, 313-325.

10. Pidd, M. Tools for Thinking: Modelling in Management Science; John Wiley and Sons: New York, NY, USA, 2003.

11. Mwale, S.M. Road sector reform: a tale of two countries: serendipity or foresight? Afri. Trans. Tech. Note. 1997, 6, 1-4.

12. Addo, S.T. Urban transport in Ghana and Africa: problems and solutions. Ghana Soc. Sci. J. 2002, 1, 1-8.

13. Litman, T. The Costs of Automobile Dependency and the Benefits of Balanced Transportation; Victoria Transport Policy Institute: Victoria, BC, Canada, 2002.

14. Wickham, J.; Lohan, M. The Social Shaping of European Urban Car System-Report on Workpackage 1.2 "Typology of Car Systems"; Employment Research Centre: Dublin, Ireland, 1999.

15. Obeng-Odoom, F. The future of our cities. Cities 2009, 26, 49-53.

16. Faiz, A; Gautama, S.; Burki, B. Air pollution from motor vehicles: issues and options for Latin American countries. Sci. Total. Environ. 1995, 169, 303-310.

17. Kutzbach, M.J. Motorization in developing countries: causes, consequences, and effectiveness of policy options. J. Urban. Econ. 2009, 65, 154-166.

18. Mahendra, A. Vehicle restrictions in four Latin American cities. Is congestion pricing possible? Transp. Rev. 2009, 28, 105-133.

19. Cervero, R.; Golub, A. Informal transport: a global perspective. Trans. Policy 2007, 14, 445-457.

20. Lautso, K.; Toivanen, S. SPARTACUS system for analysing urban sustainability. Transp. Res. Rec. 1999, 1670, 35-46.

21. Springael, J.; Kunsch, P.L.; Brans, J.P. A multicriteria-based system dynamics modeling of traffic congestion caused by urban commuters. Cejors 2002, 10, 81-97. 
22. Wegener, M. Overview of land-use transport models. In Transport Geography and Spatial Systems, Handbooks in Transport; Hensher, D.A., Button, K., Eds.; Pergamon Press: Oxford, UK, 2003; Vol. 5.

23. Barlas, Y. System Dynamics: Systemic Feedback Modeling for Policy Analysis: Encyclopedia for Life Support Systems; UNESCO Publishing: Oxford, UK, 2002.

24. Sterman, J. Business Dynamics. Systems Thinking and Modelling for a Complex World; McGraw-Hill: Boston, MA, USA, 2000.

25. Forrester J.W. Urban Dynamics; Pegasus Communications: Waltham, MT, USA, 1969.

26. Kanyama, A.; Carlsson-Kanyama, A.; Anna-Lisa L.; Lupala, J. Public Transport in Dar-es-Salaam, Tanzania: Institutional Challenges and Opportunity for a Sustainable Transport System; Royal Institute of Technology: Stockholm, Sweden, 2009.

27. Forrester, J.W. World Dynamics; Wright-Allen Press: Cambridge, MA, USA, 1971.

28. Meadows, D.H.; Meadows, D.L.; Randers, J.; Behrens, W.W., III. The Limits to Growth: A Report for the Club of Rome's Project on the Predicament of Mankind; Universe Books: New York, NY, USA, 1972.

29. Duran-Encalada, J.A.; Paucar-Caceres, A. System dynamics urban sustainability model for Puerto Aura in Puebla, Mexico. Syst. Pract. Action Res. 2009, 22, 77-99.

30. Schipper, L; Marie-Lilliu, C.; Gorham, R. Flexing the Link between Transport and Greenhouse Gas Emission: A Path for the World Bank; International Energy Agency: Paris, France, 2000.

31. Dhakal, S.; Schipper, L. Transport and environment in Asian cities: reshaping the issues and opportunities into a holistic framework. Int. Rev. Environ. Strateg. 2005, 5, 399-424.

(C) 2010 by the authors; licensee Molecular Diversity Preservation International, Basel, Switzerland. This article is an open-access article distributed under the terms and conditions of the Creative Commons Attribution license (http://creativecommons.org/licenses/by/3.0/). 